\title{
Effects of electromyostimulation training on jumping and muscle strength in football players
}

\author{
Kale M. ${ }^{\mathrm{ABCDE}}$, Gurol B. ${ }^{\mathrm{BDE}}$ \\ Department of Coaching Education, Faculty of Sport Sciences, Eskişehir Technical University, Eskişehir, Turkey
}

Authors' Contribution: A - Study design; B - Data collection; C - Statistical analysis; D - Manuscript Preparation; E - Funds Collection.

\begin{abstract}
Purpose: $\quad$ Electromyostimulation is a popular training to increase muscle strength during the last years. The aim of this study was to investigate effects of electromyostimulation training on jumping and muscle strength in football players.

Material: $\quad$ Volunteered 23 football players between the ages of 18 to 24 were divided into experimental and control groups with simple random sampling. Both groups continued to regular training. Experimental group had additional electromyostimulation training for 6-week, 3-time a week, and 20min a day. Pre- and post-training squat and countermovement jumps, peak torques of dominant and non-dominant knee extensor and flexor muscles were tested. Angular velocities of isokinetic dynamometer were 60,180 , and $300^{\circ} \mathrm{s}^{-1}$. Pre- and posttest comparisons within the groups were analyzed.

Results: $\quad$ There were no significant differences between pre- and post-test for isokinetic knee strength parameters at all angular velocities of experimental group. However, control group had significant pre- and post-test differences in dominant and non-dominant knee extension and flexion peak torque values.

Conclusions: Electromyostimulation and regular training in-season had no effect on the isokinetic strength parameters. On the other hand, the regular training in-season has increased isokinetic strength. Electromyostimulation training additional to regular training may have detrimental effects on outcomes of concurrent training in football players.

Keywords: electromyostimulation, squat jump, countermovement, jump, isokinetic, strength.
\end{abstract}

\section{Introduction}

The electromyostimulation (EMS) through the skin cause changes in neuromuscular transmission speed during the voluntary contraction [1]. In this method, the nerves and muscles are stimulated at various intensities and frequencies via electrodes on the skin using electrical currents. The effectiveness of EMS is related to the intensity of electrical currents applied during training. The key factor in the effectiveness of EMS is the maximum tolerable application of current intensity to maximize muscle tension. EMS is also known as neuromuscular electrical stimulation. When it is applied in sufficient, it causes a significant increase in maximal voluntary contraction ability. Therefore, EMS is used in athletes as a part of strength training to increase knee extensor strength [2, 3], enhance squat jump (SJ) [2, 4, 5] and countermovement jump (CMJ) [5, 6].

The interest in EMS has increased after Kots claimed that force gains of up to $40 \%$ in elite athletes [7]. It is used a training program in short-time with high-frequency electrical muscle stimulation. Although there was muscle strength development in EMS, the development of muscle strength was not more than that of in voluntary exercise [8]. Strength development in traditional strength training often occurs because of dynamic movements during the muscle contraction including the agonist-antagonist coordination. It is necessary that EMS has to be performed in more repetition at the angles of each muscle movement. However, in traditional strength training (e.g; leg press),

\footnotetext{
(c) Kale M., Gurol B., 2019

doi:10.15561/20755279.2019.0505
}

different muscle groups (gluteal, hamstrings, quadriceps) can contract at the same time. The pain that cannot be tolerated during the EMS training is the most important reason for hindering the strength development.

EMS creates a proprioceptive input in the extremity because of the afferent and efferent stimulation [9]. If EMS is combined with voluntary contractions, it constitutes a statistically significant increase in muscle strength in healthy individuals [10]. However, it must be run with at least $60 \%$ of maximal voluntary contraction for the formation of muscular development [11]. The replication of this situation via EMS can only be managed by increasing the stimulation intensity up to tolerated by the muscle.

EMS training produces knee extensor strength development $[2,3,12$,] and vertical jump improvement [13]. However, Porcari et al. showed that it did not enhance knee extensor and flexor strength. The studies based on a single joint including knee [2, 3, 12, 13], elbow [10], and shoulder [14, 15], and the lower third of the sternum [16] support that the EMS training produces strength development. On the other hand, detailed studies involving strength development based on multi-joint is necessary.

The examination of effects of EMS on muscle strength will be significant benefits from performance training in those who do explosive strength based exercises. It is important because EMS constitute a new variation instead of traditional dynamic strength training. The purpose of this study was to investigate effects of EMS training on jumping and muscle strength in football players. 


\section{Material and Methods}

\section{Participants}

Twenty-three male football players between the ages of 18 to 24 who didn't have any leg injuries last one year volunteered to participate in this study. The participants were divided into 2 groups with simple random sampling. Ten football players sat off the experimental group (EG) (age $=20.2 \pm 2.1$ year, training age $=98.4 \pm 32.4$ month, body height $=173.6 \pm 6.1 \mathrm{~cm}$, body weight $=65.0 \pm 5.6 \mathrm{~kg})$. The other 13 players sat off the control group (CG) (age= $21.9 \pm 0.3$ year, training age $=84.9 \pm 22.7$ month, body height $=177.2 \pm 5.4 \mathrm{~cm}$, body weight $=69.9 \pm 7.1 \mathrm{~kg}$ ). Both groups were supposed to perform regular training but EG also perform EMS. The players were free to discontinue the study at any time. They signed in their statements of informed consent after the procedures and probable risks had been explained to them. Osmangazi University Ethical Advisory Committee approved the study (2010/214) prior to the commencement of testing. The players were randomly participated into the test protocols.

\section{Procedures}

EG performed EMS in addition to regular training at the frequency of $100 \mathrm{~Hz}$, the current width of $400 \mu \mathrm{s}$. A stimulator device (Compex 3 Professional, Medicompex SA, Switzerland) was used with self-adhesive electrodes placed on dominant leg (D) and non-dominant leg (ND). The electrodes were placed on motor points of quadriceps muscles (vastus medialis, vastus lateralis, rectus femoris). The current intensity in this frequency was increased until it initiated the muscle contraction. CG performed regular training. The EMS training was performed 30min a day, 3 days a week that lasted in 6 weeks. Each participant was familiarized with training and testing procedures within one week before the training and testing. After the familiarization, each participant participated in one test a day that lasted about $30 \mathrm{~min}$. After anthropometric measurements, SJ and CMJ were tested by the digital wireless device (Freejump, Rome, Italy). The device fixed on athlete's lumbar area. The peak torques to be exhibited on the muscles of D and ND knee joints were determined by using isokinetic testing device (Humac Norm Testing \& Rehabilitation System, Stoughton, USA). The peak torques were tested with three different angular velocities $\left(60,180\right.$, and $\left.300^{\circ} \cdot \mathrm{s}^{-1}\right)$. Pre- and post-training differences depending on these two types of training on jump and muscle strength were investigated. The average of the two measurements in anthropometric measurements were evaluated for descriptive statistics. The best test performance obtained from two trials that were performed in jump tests were evaluated for statistical analyses. The isokinetic tests were performed 5 times for each knee joint at 3 different angular velocities. The highest torque values of these 5 trials were evaluated for statistical analyses.

\section{Training Design}

Regular Training: All participants took part in the study played in an official league match in each week. They performed regular training, which was followed by a resting day after the match in the official season. Players were performed speed, strength, endurance training on the first day and third training day of the regular weekly training. The training week was followed by technical and tactic-specific football training for $60 \mathrm{~min}$ on the second and fourth day. Speed training [2 x $(4 \times 40 \mathrm{~m})]$ was performed with 3-4 min among reps and 4-6 min between sets. Strength training involved the maintenance training. It was consisted of 7 exercises (half squat, bench press, lat pull down, leg extension, leg curl, shoulder press, and calf raise). Each exercise was 90\% intensity, 3 × 3 reps with 3-5 min among the sets and. There were 4-6 min recoveries after each exercise. Endurance training involved the extensive tempo (135-140 beat.min $\left.{ }^{-1}\right)$. It was consisted of $10 \times 200 \mathrm{~m}$ with the recovery until the heart rate decreases 120 beat. $\mathrm{min}^{-1}$ among repetitions. All players performed soccer-specific basic techniques and shooting training lasting in $40 \mathrm{~min}$ before every match day. This was the last training on the fifth day of weekly training.

Electromyostimulation Training: EMS training was conducted on the knee extensor muscles 3 days a week (18 sessions) for 6 weeks. EG participated in EMS training in addition to the regular training sessions. EMS training was on the first, third and fifth training days before the match after the resting day for six weeks. Each session lasted in $20 \mathrm{~min}$. Five min cycling on a bicycle ergometer and 5 min free dynamic stretching were used for warmup. Five min EMS application was conducted on the quadriceps muscles of D and ND (vastus medialis, vastus lateralis, rectus femoris) as 35 isometric contractions. EMS was conducted with a stimulator generating biphasic symmetrical square wave signal (Compex 3 Professional, Medicompex SA, Switzerland) at the frequency of 100 $\mathrm{Hz}$. The stimulator has the current width of $400 \mu \mathrm{s}$ as previously recommended $[4,8]$. The work cycle of the stimulator was adjusted to $1.5 \mathrm{~s}$ increased current and $0.5 \mathrm{~s}$ decreased current. Contraction time was 10s and resting period was $3 \mathrm{~s}$. Every athlete sat on a chair and while their knees were in $90^{\circ}$ flexion position. Chronaxie value was determined on an individual basis, and the current level was adjusted to their maximum tolerability. The motor points of the muscles were determined by using the motor point pen. Three positive electrodes $(5 \times 5 \mathrm{~cm})$ were placed as close as possible to the motor points of vastus medialis, vastus lateralis and rectus femoris muscles. Three negative electrodes $(5 \times 10 \mathrm{~cm}, 5 \times 5 \mathrm{~cm})$ were positioned as close as possible to the head of the thigh (femoral triangle). The goniometer was used to standardize the knee and hip angle.

\section{Anthropometric Measurements}

Each participant was kindly asked not to drink much water the night before the anthropometrical measurements were taken. The measurements were taken on an empty stomach as described by Lohman et al. [17]. The body height of each participant was measured with $\pm 0.1 \mathrm{~mm}$ sensitivity through stadiometer (Holtain, UK). It was taken as $\mathrm{cm}$ in a way that the participants were barefoot, heels together, their feet opened to each other at an angle of $60^{\circ}$. The body weight evenly distributed on both feet. Arms and palms on both sides were united to the body. 
The body was united to the vertical table of stadiometer in anatomical stand position. Eyes were focused over in the inspiration phase, the head in the frontal plane. Table of head top were placed as close as possible to the vertex point. Body weight was taken with $0.1 \mathrm{~kg}$ sensitivity in $\mathrm{kg}$. The participant was only with his shorts and barefoot in anatomical position on the laboratory bascule (Seca, Vogel \& Halke, Hamburg). His eyes were focused over. His weight evenly was distributed on both sides of his feet.

\section{Jump Tests}

A jumping measuring system (Freejump, Sensorize, Rome, Italy) with light machinery having computer software was connected to the belly through wireless waist belt. It was capable of measuring the jumping height of the participants in SJ and CMJ tests was used. After each jump, the participants had a rest for $5 \mathrm{~min}$. Participants performed two trials for each jump test and the better jump heights in the trials were evaluated statistically. The participants performed SJ in the position of knees flexed until they felt a comfortable starting position, semisquatting position. The position normally occurs at a knee angle of about $85^{\circ}[18]$ and they maintained their posture at least two to three seconds. This prevented the prestretching of muscles from any preliminary downward movement before jump. $\mathrm{CMJ}$ was performed in an upright standing position, hands kept on the hips following a preliminary downward movement by flexing the knee. The movement was approximately to the same knee angle as the starting position in SJ.

Isokinetic Strength Tests

The peak torques in concentric/concentric knee extension and flexion of D and ND were tested by isokinetic dynamometer (Humac Norm Testing \& Rehabilitation System, USA). The angular velocities of $60^{\circ} . \mathrm{s}^{-1}, 180^{\circ} . \mathrm{s}^{-}$ ${ }^{1}$, and $300^{\circ} \cdot \mathrm{s}^{-1}$ were used. Isokinetic dynamometer was calibrated at the beginning of each test day as specified by CSMI [19]. Each athlete freely warmed up before the test. The attachments of the dynamometer were set according to the anatomical structure of each participant. The mobility of the knee joint was positioned at $0-90^{\circ}$ for knee extension and flexion test. The participant was placed on a two-position seat of the dynamometer as specified by CSMI [19]. The axis rotation of the dynamometer's arm was adjusted to the level of lateral femoral epicondyle. The pad was placed to the proximal of lateral malleolus, which was fixed on the attachments of the lower leg. The preventive belts from movements of the body and quadriceps were tightened. The reference way is that three fingers can be inserted between the body and the quadriceps. During the test, each participant held the handles on each side of the seat of the dynamometer. Athletes were asked to perform maximal 5 times knee extension and flexion with $60 \mathrm{~s}$ rest intervals in the three angular velocities as recommended Davies et al. [20]. The highest torque values at each angular velocity were considered as the peak torque values. In order to adapt to angular velocity of each test and avoid form probable injuries, three training repetitions were done. The test was started after $30 \mathrm{~s}$ resting period. Each participant was encouraged verbally (push/pull) during the test with regard to the number of the repetitions left.

\section{Statistical Analysis}

SPSS 22 (SPSS Inc., Chicago, IL, USA) was used for the statistical analysis of the data. Wilcoxon $t$ test was used to determine pre- and post-test differences within the group. Probability level for statistical significance was set at $\mathrm{p} \square 0.05$. Differences in means/standard deviation (Sd), defined effect size Cohen's $d$, was calculated for groups between pre- and post-tests. Thresholds for small, medium, and large effects were $0.20,0.50$, and 0.80 , respectively [21].

\section{Results}

Results for the jumps and isokinetic knee strength parameters for EG and CG are presented in Table 1 and 2. No significant differences in pre-test results for all parameters could be found between groups.

As shown in Table 1, there are no statistically significant pre- and post-test differences in SJ and CMJ.

Table 2 described that there were no statistically significant differences between pre- and post-test at all angular velocities of EG ( $\mathrm{p}>0.05)$. However, at $60^{\circ} \mathrm{s}^{-1}$, statistically significant differences were founded between D leg pre- and post-tests of CG in EPT, FPT, and EFR $(\mathrm{d}=0.86,1.42$, and $0.85 ; \mathrm{p}<0.01,<0.05$, and $<0.05$, respectively), ND leg EPT and FPT ( $d=1.61$ and 1.88; $\mathrm{p}<0.01)$. CG had statistically significant pre- and posttest differences at $180^{\circ} \mathrm{s}^{-1}$ for D leg EPT and FTP $(\mathrm{d}=1.65$ and 2.22, $\mathrm{p}<0.01$, respectively), ND leg EPT and FTP $(\mathrm{d}=1.92$, and $195 ; \mathrm{p}<0.01)$. CG also had statistically significant pre- and post-test differences at $300^{\circ} \mathrm{s}^{-1}$ for D leg EPT, FTP and EFR $(\mathrm{d}=1.32,2.12$, and 0.67 ; $<<0.01$, respectively), ND leg EPT and FPT (d=1.62 and 1,85; $\mathrm{p}<0.01)$.

Table 1. Pre- and post-test results for SJ and CMJ for EG $(n=10)$ and $C G(n=13)$. Data are reported as mean $\pm S D$.

\begin{tabular}{lllll}
\hline Jump & Group & Pre-test & Post-test & d \\
\hline \multirow{2}{*}{ SJ $(\mathrm{cm})$} & EG & $31.9 \pm 2.9$ & $31.8 \pm 2.7$ & 0.04 \\
& CG & $36.3 \pm 6.1$ & $37.3 \pm 6.1$ & 0.16 \\
$\mathrm{CMJ}(\mathrm{cm})$ & EG & $34.8 \pm 2.7$ & $35.2 \pm 2.6$ & 0.15 \\
& CG & $39.1 \pm 6.4$ & $39.9 \pm 6.5$ & 0.12 \\
\hline
\end{tabular}


Table 2. Pre- and post-test results for isokinetic knee strength parameters at different angular velocities for $E G(n=10)$ and CG $(n=13)$. Data are reported as mean \pm SD.

\begin{tabular}{|c|c|c|c|c|c|c|}
\hline Angular velocity & Leg & Knee Parameters & Group & Pre-test & Post-test & d \\
\hline \multirow{12}{*}{$60^{\circ} \cdot \mathrm{s}^{-1}$} & \multirow{6}{*}{$D$} & \multirow{2}{*}{ EPT (Nm) } & EG & $207 \pm 43$ & $224 \pm 73$ & 0.28 \\
\hline & & & CG & $213 \pm 44$ & $263 \pm 69 * *$ & 0.86 \\
\hline & & \multirow{2}{*}{$\mathrm{FPT}(\mathrm{Nm})$} & EG & $148 \pm 32$ & $164 \pm 54$ & 0.36 \\
\hline & & & CG & $141 \pm 24$ & $197 \pm 50 *$ & 1.42 \\
\hline & & \multirow{2}{*}{ EFR } & EG & $0.73 \pm 0.14$ & $0.74 \pm 0.10$ & 0.08 \\
\hline & & & CG & $0.67 \pm 0.09$ & $0.76 \pm 0.12^{*}$ & 0.85 \\
\hline & \multirow{6}{*}{ ND } & \multirow{2}{*}{ EPT (Nm) } & EG & $198 \pm 41$ & $199 \pm 60$ & 0.02 \\
\hline & & & CG & $191 \pm 40$ & $275 \pm 62 * *$ & 1.61 \\
\hline & & \multirow{2}{*}{ FPT (Nm) } & EG & $138 \pm 29$ & $137 \pm 36$ & 0.03 \\
\hline & & & CG & $132 \pm 18$ & $199 \pm 47 * *$ & 1.88 \\
\hline & & \multirow{2}{*}{ EFR } & EG & $0.71 \pm 0.10$ & $0.70 \pm 0.12$ & 0.09 \\
\hline & & & CG & $0.72 \pm 0.15$ & $0.73 \pm 0.09$ & 0.08 \\
\hline \multirow{12}{*}{$180^{\circ} \cdot \mathrm{s}^{-1}$} & \multirow{6}{*}{ D } & \multirow{2}{*}{$\mathrm{EPT}(\mathrm{Nm})$} & EG & $134 \pm 25$ & $145 \pm 43$ & 0.31 \\
\hline & & & CG & $140 \pm 25$ & $195 \pm 40 * *$ & 1.65 \\
\hline & & \multirow{2}{*}{ FPT (Nm) } & EG & $112 \pm 22$ & $121 \pm 25$ & 0.38 \\
\hline & & & CG & $108 \pm 17$ & $165 \pm 32 * *$ & 2.22 \\
\hline & & \multirow{2}{*}{ EFR } & EG & $0.85 \pm 0.15$ & $0.87 \pm 0.14$ & 0.14 \\
\hline & & & CG & $0.78 \pm 0.14$ & $0.86 \pm 0.12$ & 0.61 \\
\hline & \multirow{6}{*}{ ND } & \multirow{2}{*}{ EPT (Nm) } & EG & $135 \pm 32$ & $147 \pm 45$ & 0.30 \\
\hline & & & CG & $128 \pm 25$ & $192 \pm 40 * *$ & 1.92 \\
\hline & & \multirow{2}{*}{ FPT (Nm) } & EG & $109 \pm 23$ & $117 \pm 27$ & 0.32 \\
\hline & & & CG & $106 \pm 11$ & $158 \pm 36 * *$ & 1.95 \\
\hline & & \multirow{2}{*}{ EFR } & EG & $0.82 \pm 0.11$ & $0.80 \pm 0.13$ & 0.17 \\
\hline & & & CG & $0.85 \pm 0.16$ & $0.83 \pm 0.12$ & 0.14 \\
\hline \multirow{12}{*}{$300^{\circ} \cdot s^{-1}$} & \multirow{6}{*}{$\mathrm{D}$} & \multirow{2}{*}{ EPT (Nm) } & EG & $102 \pm 20$ & $105 \pm 28$ & 0.12 \\
\hline & & & CG & $108 \pm 23$ & $145 \pm 32 * *$ & 1.32 \\
\hline & & \multirow{2}{*}{$\mathrm{FPT}(\mathrm{Nm})$} & EG & $90 \pm 14$ & $91 \pm 20$ & 0.06 \\
\hline & & & CG & $86 \pm 13$ & $131 \pm 27^{* *}$ & 2.12 \\
\hline & & \multirow{2}{*}{ EFR } & EG & $0.89 \pm 0.12$ & $0.88 \pm 0.10$ & 0.09 \\
\hline & & & CG & $0.81 \pm 0.14$ & $0.91 \pm 0.16^{* *}$ & 0.67 \\
\hline & \multirow{6}{*}{ ND } & \multirow{2}{*}{ EPT (Nm) } & EG & $101 \pm 20$ & $108 \pm 36$ & 0.24 \\
\hline & & & CG & $98 \pm 16$ & $138 \pm 31^{* *}$ & 1.62 \\
\hline & & \multirow{2}{*}{$\mathrm{FPT}(\mathrm{Nm})$} & EG & $85 \pm 12$ & $92 \pm 20$ & 0.42 \\
\hline & & & CG & $86 \pm 15$ & $123 \pm 24^{* *}$ & 1.85 \\
\hline & & \multirow{2}{*}{ EFR } & EG & $0.84 \pm 0.90$ & $0.89 \pm 0.12$ & 0.47 \\
\hline & & & CG & $0.90 \pm 0.20$ & $0.91 \pm 0.12$ & 0.06 \\
\hline
\end{tabular}

Notes: ${ }^{*} p<0.05 ;{ }^{*} p<0.01$; D: Dominant; ND: Non-dominant; EPT: Extension Peak Torque; FPT: Flexion Peak Torque; EFR: Extension/Flexion Ratio.

\section{Discussion}

In this study, no statistically significant pre- and post training differences in SJ and CMJ for both groups were found. However, the increase trends of SJ and CMJ in $\mathrm{CG}$ group and also CMJ in EG were observed. In terms of $\mathrm{CMJ}_{-} \mathrm{SJ}_{\text {dif }}$, the increase trend in the EG and decrease trend in the CG were observed. Gregory and Bickel [22] explained that motor unit excitation in low strength levels provided fast motor unit activation with new stresses by EMS. Malatesta et al. [23] found that jumping in volleyball players were improved after 4 weeks by a weekly $36 \mathrm{~min}$ short-term training. Maffiuletti et al. [2],
Brocherie et al. [3], Malatesta et al. [23], Maffiuletti, et al. [24] indicated that EMS training could improve the jumping performance. They also indicated that $40-50 \mathrm{~Hz}$ frequencies could provide jumping acquisition. Deley et al. [25] reported that EMS to quadriceps muscles were combined with jumping and sprint provides a better force development. In this study, EMS in addition to the regular training had no statistically significant pre- and post-training differences in SJ, CMJ. However, when examining the averages, the increase trend was observed in CMJ (34.8 $\pm 2.7 \mathrm{~cm}$ vs. $35.2 \pm 2.6 \mathrm{~cm})$. Although Malatesta et al. [23] found an increase in SJ and CMJ after 4-week 
EMS training, they didn't find any increases after 10days of EMS training. Jubeau et al. [26] explained their result appeared after EMS as the early (increasing muscle activation and EMG activity) and late adaptation (an increase in the amplitude of the spinal reflex and decrease in co-activation) of the nervous system. Maletesta et al. [23] indicated that EMS caused the increase in neural drive or preferable activation of rapid muscle fibers. They explained that it also improved explosive movements by taking the control of the neuromuscular properties optimum situation in the complex dynamic movements. Gulick et al. [27]'s study supported Maletesta et al [23]'s study that the vertical jumping showed an increase with the jumping training performed together with EMS application for 6 weeks.

The order of motor unit excitation in the voluntary muscle contraction is based on the stimuli intensity. The progresses are to a large motor unit from a small motor unit. In addition, sub-maximal voluntary muscle contraction only excites small muscle units. As independent of the current intensity with EMS, the large motor units are excited before the small motor units. This situation depends on the mass of the dendrites and their morphological organization in the area exposed to stimulation [28]. According to Knaflitz et al. [29], EMS has a tendency to reverse the motor unit excitation during voluntary contraction. He stated that also EMS prefers to stimulate the fast twitch fibers in the large area of the fiber. Paillard et al. [13] indicated that EMS application provides better synchronization during muscle movement of the fast twitch fibers. They showed that the muscle power is improved and when the EMS application is combined with the sport-specific training involving the voluntary muscle movements. Besides, it develops specific neuromuscular adaptations that can be transferred to the complex movement such as vertical jump. In this study, it was found that EMS application had no statistically significant effect on SJ. In terms of CMJ, while there was no a significant difference, the increase trend was observed after EMS application. Deley et al. [25] indicated that a 6-week EMS in addition to gymnastic training resulted in significant increases in SJ and CMJ (respectively, $20.9 \pm 8.3 \%, 20.4 \pm 6.2 \%, p<0.05$ ). Maffiuletti et al. [6] reported that an increase was detected in 2-3 weeks after the end of EMS application in CMJ. They also stated that this increase could be maintained by the other training techniques such as plyometric training. The explained reason was the lack of anaerobic power development in the first month of EMS application. According to Gregory and Bickel [22] motor unit excitation by EMS was slightly different from normal muscle activation (not selective, sizes were fixed, and gave temporarily synchronization, relatively provided fast motor unit activity in low strength levels). Maffiuletti et al. [24] stated that EMS training in a short-term period in well-trained athletes brings about a new form of stress. He explained that this stress involves the adaptive changes such as increased muscle activation to the central nervous system.

In the study of Billot et al. [30], 3-5 weeks of EMS training did not statistically increase SJ and CMJ. Malatesta et al. [23] and Herrero et al. [31] indicated that a 4-week EMS training did not increase in SJ and CMJ. In addition to this, Brocherie et al. [3] found that a 3-week of EMS training statistically significant decreased jumping in hockey players. Maffiuletti et al. [2] stated that the short-term EMS application caused to tiredness and excessive training. It also required a recovery period to allow an increase in jump performance after the EMS application.

There were several studies that were shown long-term applications of EMS were changed the jump performance $[2,22-25,30,31]$. However, there were no statistically significant differences in the jumping performances in these studies. These reasons that were not possible to a certain conclusion about the optimal EMS to be applied to increase the jumping performance.

No statistically significant pre- and post-training differences were found in isokinetic knee extensor and flexor strength parameters at 3 angular velocities in EG. There were statistically significant pre- and post-training differences in the parameters of $\mathrm{D}$ and ND leg isokinetic knee extensor and flexor strength at 3 angular velocities in CG. The results of the current study supported the studies of Halback and Straus [32], and Bax et al. [33]. Also Paillard et al. [13] didn't found significant difference between a combined training (stair climbing and local EMS application) and local EMS training in isokinetic quadriceps strength. In addition to this, Locicero [34] indicated that the knee isokinetic strength changed related to EMS was not more than that of occurred in the conventional strength training. Unlike this study, Deley et al. [25] stated that 6 weeks of EMS application in addition to gymnastic training significantly increased isokinetic knee extensor torque values (at 60 and $240^{\circ} . \mathrm{s}^{-1}$ ) (respectively $35.3 \pm 11.8 \%, 50.6 \pm 7.7 \%$; $<<0.05)$. In Kemmler et al. [35]'s study, the whole body EMS training caused an increase in the strength of the leg extensors. Nobbs and Rhodes [36] expressed that muscle contractions with EMS were associated with strength production capacity in the voluntary isometric contractions. Cauraugh and Kim [37] found that EMS with $50 \mathrm{~Hz}$ provided more than $30 \%$ increase of isokinetic strength at $200^{\circ} . \mathrm{s}^{-1}$ for the fast twitch fibers. They indicated that the strength increases in fast twitch fibers came from the increase in the motor unit excitation frequencies by high intensity workouts. The reason is that EMS activated efferent of motor units. They also speculated that EMS training could excite the fast twitch fibers thanks to an increase in their myelination.

\section{Conclusion}

In conclusion, EMS and regular training in-season had no effect on the isokinetic strength parameters. On the other hand, the regular training in-season increased isokinetic strength. The intervention in regular training might be a detrimental effect on the outcome of the football players' concurrent training. CG showed improvements on many of the isokinetic strength test results, which were not apparent in the EG. In the future studies, the physiological 
responses of the players especially the measurement of internal traffic structure about post activation potentiating for explosive activities in competitive sports in accordance by Gołas et al. [38, 39] to the extended training and the effects of EMS in different amplitude and frequency can be examined.

\section{Acknowledgements}

This present paper was supported by Anadolu University Scientific Research Projects by Project
1001S82. Special thanks are given to Evrensel Heper, Celil Kaçoğlu, İzzet Kırkaya for their assistance in the preparation of measurement settings. Special thanks are also given to Eskişehirspor Football Club for giving permission to U19 and A2 football players to participate in the study.

\section{Conflicts of Interest}

The authors declare no conflicts of interest.

\section{References}

1. Marqueste T, Hug F, Decherchi P, Mes Y. Changes in neuromuscular function after training by functional electrical stimulation. Muscle \& Nevre, 2003;28(2):181- 188. https://doi.org/10.1002/mus.10408

2. Maffiuletti NA, Cometti G, Amiridis IG, Martin A, Pousson $\mathrm{M}$, Chatard JC. The effects of electromyostimulation training and basketball practice on muscle strength and jumping ability. InternationalJournalofSports Medicine, 2000;21(6):437-443. https://doi.org/10.1055/s-2000-3837

3. Brocherie F, Babault N, Cometti G, Maffiuletti N, Chatard JC. Electrostimulation training effects on the physical performance of ice hockey players. Medicine and Science in Sports and Exercise, 2005;37(3):455- 460. https://doi.org/10.1249/01.MSS.0000155396.51293.9F

4. Babault N, Cometti G, Bernardin M, Pousson M, Chatard JC. Effects of electromyostimulation training on muscle strength and power of elite rugby players. Journal of Strength and Conditioning Research, 2007;21(2):431- 437. https://doi.org/10.1519/00124278-200705000-00025

5. Filipovic A, Kleinoeder H, Doermann U, Mester J. Electromyostimulation - a systematic review of the effects of different electromyostimulation methods on selected strength parameters in trained and elite athletes. Journal of Strength and Conditioning Research, 2012;26(9):2600- 2614. https://doi.org/10.1519/JSC.0b013e31823f2cd1

6. Maffiuletti NA, Bramanti J, Jubeau M, Bizzini M, Deley G, Cometti G. Feasibility and efficacy of progressive electrostimulation strength training for competitive tennis players. Journal of Strength and Conditioning Research, 2009;23(2):677- 682. https://doi.org/10.1519/JSC.0b013e318196b784

7. Ward AR, Shkuratova N. Russian electrical stimulation: The early experiments. Physical Therapy, 2002;82(10):10191030.

8. Hainaut K, Duchateau J. Neuromuscular electrical stimulation and voluntary exercise. Sports Medicine, 1992;14(2):100- 113. https://doi.org/10.2165/00007256-199214020-00003

9. Lindquist AR, Prado CL, Barros RM, Mattioli R, Costa PH, SalviniTF.Gaittraining combiningpartialbody-weightsupport a treadmill, and functional electrical stimulation: effects on poststroke gait. Physical Therapy, 2007;87(9):1144- 1154. https://doi.org/10.2522/ptj.20050384

10.Holcomb WR. Effect of training with neuromuscular electrical stimulation on elbow flexion strength. Journal of Sports Science and Medicine, 2006;5:276-281.

11.Porcari JP, McLean KP, Foster C, Kernozek T, Crenshaw B, Swenson C. Effects of electrical muscle stimulation on body composition, musclestrength, and physicalappearance.Journal of Strength and Conditioning Research, 2002;16(2):165- 172. https://doi.org/10.1519/00124278-200205000-00001

12.Alon G, Smith GV. Tolerance and conditioning to neuro- muscular electrical stimulation within and between sessions and gender. Journal of Sports Science and Medicine, 2005;4(4):395-405.

13.Paillard T, Noe F, Bernard N, Dupui P, Hazard C. Effects of two types of neuromuscular electrical stimulation training on vertical jump performance. Journal of Strength and Conditioning Research, 2008;22(4):1273- 1278. https://doi.org/10.1519/JSC.0b013e3181739e9c

14.Baker LL, Parker K. Neuromuscular electrical stimulation of the muscles surrounding the shoulder. Physical Therapy, 1986;66(12):1930- 1937. https://doi.org/10.1093/ptj/66.12.1930

15.Pichon F, Chatard JC, Martin A, Cometti G. Electrical stimulation and swimming performance. Medicine and Science in Sports and Exercise, 1995;27(12):1671- 1676. https://doi.org/10.1249/00005768-199512000-00014

16.Porcari JP, Miller J, Cornwell K, Foster C, Gibson M, McLean $\mathrm{K}$, Kernozek T. The effects of neuromuscular electrical stimulation training of abdominal strength, endurance, and selected anthropometric measures. Journal of Sports Science and Medicine, 2005;4(1):66-75.

17.Lohman TG, Roche AF, Martorel R. Anthropometric Standardization Manuel. Champaign, IL; Human Kinetics; 1988.

18.Bosco C, Komi PV. Mechanical characteristics and fiber composition of human leg extensor muscle. European Journal of Applied Physiology Occupational Physiology, 1979;41(4):275- 84. https://doi.org/10.1007/BF00429744

19.CSMI. Humac ${ }^{\circledR N o r m}{ }^{T M}$ Testing \& Rehabilitation System User Guide Model 770. Stoughton, MA; 2003.

20.Davies GJ, Heiderschheit B, Brinks K. Isokinetic Test Interpretation. In: Brown L, editor, Isokinetics in Human Performance. Champaign, IL: Human Kinetics; 2000.P.3-24.

21.Cohen J. Statistical Power Analysis for the Behavioral Sciences, $2^{\text {nd }}$ Edition. Hillsdale, NJ: Lawrence Erlbaum Associates; 1988.

22.Gregory CM, Bickel CS. Recruitment patterns in human skeletal muscle during electrical stimulation. Physical Therapy, 2005;85(4):358-364.

23.Malatesta D, Cattaneo F, Dugnani S, Maffiuletti NA. Effects of electromyostimulation training and volleyball practice on jumping ability. Journal of Strength and Conditioning Research, 2003;17(3):573- 579. https://doi.org/10.1519/00124278-200308000-00025

24.Maffiuletti NA, Dugnani S, Folz M, Di Pierno E, Mauro F. Effect of combined electrostimulation and plyometric training on vertical jump height. Medicine and Science in Sports and Exercise, 2002;34(10):1638- 1644. https://doi.org/10.1097/00005768-200210000-00016

25.Deley G, Cometti C, Fatnassi A, Paizis C, Babault N. Effects of combined electromyostimulation and 
gymnastics training in prepubertal girl. Journal of Strength and Conditioning Research, 2011;25(2):520- 526. https://doi.org/10.1519/JSC.0b013e3181bac451

26.Jubeau M, Zory R, Gondin J, Martin A, Maffiuletti NA. Late neural adaptations to electrostimulation resistance training of the plantar flexor muscles. European Journal of Applied Physiology, 2006;98(2):202- 211. https://doi.org/10.1007/s00421-006-0264-z

27.Gulick DT, Castel JC, Palermo FX, Draper DO. Effect of pattern electrical neuromuscular stimulation on vertical jump in colleagiate athletes. Sports Health, 2011;3(2):152- 157. https://doi.org/10.1177/1941738110397871

28.Feiereisen P, Duchateau J, Hainaut K. Motor unit recruitment order during voluntary and electrically induced contractions in the tibialis anterior. Experimental Brain Research, 1997;114(1):117- 23. https://doi.org/10.1007/PL00005610

29.Knaflitz M, Merletti R, De Luca CJ. Inference of motor unit recruitment order in voluntary and electrically elicited contractions Journal of Applied Physiology, 1990;68(4):1657- 1667. https://doi.org/10.1152/jappl.1990.68.4.1657

30.Billot M, Martin A, Paizis C, Cometti C, Babault N. Effects of a electrostimulation training program on strength, jumping, and kicking capacities in soccer players Journal of Strength and Conditioning Research, 2010;24(5):1407- 1413. https://doi.org/10.1519/JSC.0b013e3181d43790

31.Herrero JA, Izquierdo $M$, Maffiuletti NA, GarciaLopez J. Electromyostimulation and plyometric training effects on jumping and sprint time. International Journal of Sports Medicine, 2006;27(7):533- 539. https://doi.org/10.1055/s-2005-865845

32.Halback J, Straus D. Comparison of electro-myo stimulation to isokinetic training in increasing power of the knee extensor mechanism. The Journal of Orthopaedic and Sports Physical Therapy, 1980;2(1):20- 24. https://doi.org/10.2519/jospt.1980.2.1.20

33.Bax L, Staes F, Verhagen A. Does neuromuscular electrical stimulation strengthen the quadriceps femoris? A systematic review of randomized controlled trials. Sports Medicine, 2005;35(3):191- 212. https://doi.org/10.2165/00007256-200535030-00002

34.Locicero RD. The effect of electrical stimulation on isometric and isokinetic knee extension torque: Interaction of the Kinestim Electrical Stimulator and the Cybex II. The Journal of Orthopaedic and Sports Physical Therapy, 1991;13(3):143- 148. https://doi.org/10.2519/jospt.1991.13.3.143

35.KemmlerW, Schliffka R, Mayhew JL, Von Stenge1S. Effects of whole-body electromyostimulation on resting metabolic rate, body compositon, and maximum strength in postmenopausal women: The training and electrostimulation trial. Journal of Strength and Conditioning Research, 2010;24(7):1880- 1887. https://doi.org/10.1519/JSC.0b013e3181ddaeee

36.Nobbs L, Rhodes EC. The effect of electrical stimulation and isokinetic exercise on muscular power of the quadriceps femoris. The Journal of Orthopaedic and Sports Physical Therapy, 1986;8(5):260- 268. https://doi.org/10.2519/jospt.1986.8.5.260

37. Cauraugh $\mathrm{JH}$, Kim S. Progress toward motor recovery with active neuromuscular stimulation: muscle activation pattern evidence after a stroke. Journal of Neurological Sciences, 2003;207(1-2):25- 29. https://doi.org/10.1016/S0022-510X(02)00355-6

38.Gołas A, Maszczyk A, Zajac A, Mikołajec K, Petr Stastny P. Optimizing post activation potentiation for explosive activities in competitive sports. Journal of Human Kinetics, 2016;1(52):95- 106. https://doi.org/10.1515/hukin-2015-0197

39.Golas A, Wilk M, Stastny P, Maszczyk A, Pajerska $\mathrm{K}$, and Zajac A. Optimizing half squat postactivation potential load in squat jump training for eliciting relative maximal power in ski jumpers. Journal of Strength and Conditioning Research, 2017;31(11):3010- 3017. https://doi.org/10.1519/JSC.0000000000001917

\section{Information about the authors:}

Kale M. (Corresponding Author); Dr., Assoc. Prof.; http://orcid.org/0000-0002-1960-2234; mkale@eskisehir.edu.tr; Department of Coaching Education, Faculty of Sport Sciences, Eskişehir Technical University; Eskişehir, Turkey.

Gurol B.; Dr., Assist. Prof.; http://orcid.org/0000-0002-3372-617X; bgurol@eskisehir.edu.tr; Department of Coaching Education, Faculty of Sport Sciences, Eskişehir Technical University; Eskişehir, Turkey.

\section{Cite this article as:}

Kale M, Gurol B. Effects of electromyostimulation training on jumping and muscle strength in football players. Physical education of students, 2019;23(5):242-248. https://doi.org/10.15561/20755279.2019.0505

This is an Open Access article distributed under the terms of the Creative Commons Attribution License, which permits unrestricted use, distribution, and reproduction in any medium, provided the original work is properly cited http://creativecommons.org/licenses/by/4.0/deed.en

Received: 18.09.2019

Accepted: 19.10.2019; Published: 26.10.2019 